\title{
Marine pharmacology: an ocean to explore novel drugs
}

\author{
Vadlakonda Sruthi, Nagur Sharone Grace*, Monica N., Valishetti Manoj Kumar
}

Department of Pharmacology, Osmania Medical College, Hyderabad, Telangana, India

\author{
Received: 11 February 2020 \\ Revised: 17 March 2020 \\ Accepted: 18 March 2020 \\ *Correspondence: \\ Dr. Nagur Sharone Grace, \\ Email: nagursharongrace@gmail.com
}

Copyright: ( $)$ the author(s), publisher and licensee Medip Academy. This is an open-access article distributed under the terms of the Creative Commons Attribution Non-Commercial License, which permits unrestricted non-commercial use, distribution, and reproduction in any medium, provided the original work is properly cited.

\begin{abstract}
The rise in burden of diseases and treatment failure demands discovery of novel compounds. Exploiting natural sources which include territory of land and water in potential manner paves the way for significant future innovations in drug discovery. Marine environment has striking functionalities in its skeleton that has fascinated scientists to show enormous interest in investigation of new compounds. Marine sponges, algae, tunicates, sea whip etc. from the marine pipeline are the important sources for biological active compounds. Recent technology advancements further added to the domain of drug research in isolation and evaluation of marine derived products. To date, significant number of compounds have been isolated. Wide range of antibacterial, anti-inflammatory, antiparasitic, neuroprotective, antiviral, anticancer, analgesic, antimicrobial, antimalarial compounds have been pursued in control and management of diseases. These represent marine ecosystem as a hopeful resource in discovery of novel compounds with ideal starting point in scaffolding additional screening of natural marine products. This is review of abstracting on history, lead development process in identifying and comprehending basic nature of compounds that is promising initial step towards unique pharmacological design, the triumph of approved and ongoing trails, brief depiction on current status and challenges being faced in marine drug discovery field.
\end{abstract}

Keywords: Marine pharmacology, Sources, Classification, Drug discovery, PUFA, Challenges

\section{INTRODUCTION}

Marine pharmacology is a part of pharmaceutical sciences that centers around the substances with dynamic pharmacological properties presenting marine animals and plants . ${ }^{1}$ Oceans contain over $80 \%$ of vivid flora and fauna on the planet. Marine living beings, for example, wipes, tunicates, delicate corals, nudibranchs, ocean bunnies, molluscs, echinoderms, bryozoans, prawns, shells, ocean slugs and marine microorganisms are the roots of bioactive mixes. ${ }^{2}$ As defense mechanism, marine invertebrates release toxic compounds to protect onslaught of predators which gave scope to scientists to study as secondary metabolites. The mechanism by which they prevent encroachment interact with the similar enzymes and receptors involved in human disease processes. With the advent of new and inevitable human diseases marine pharmacology comes in play with the innovation to explore novel drugs.

\section{HISTORY}

Benefits of marine medicine has been employed by mankind for thousands of years. Evidence of Bathini fish in treatment of asthma, oyster powder in GIT disturbances, pearl oxide in treatment of $\mathrm{TB}$, dried sea horses for respiratory system and sexual function proves that.

In 1940s, cephalosporin C produced by fungus acremonium chrysogenum isolated from Mediterranean Sea near by Sardinia, commenced for the initiation of cephalosporin class of antibiotics. Authentic marine drug development started with the discovery of spongothymidine and spongouridine in 1950s from the 
Caribbean sponge tethya crypta (Werner Bergmann). In 1969 anti-cancer drug cytarabine (Ara-C) and 1976 antiviral drug vidarabine (Ara-A) derived from arabinose nucleosides isolated from shallow water marine sponge collected off the coast of Florida.

Shimomura and two American scientists shared the 2008 Nobel prize for discovery and development of a jelly fish protein that later contributed to anti-cancer studies.

\section{MARINE PHARMACOLOGY IN INDIA}

Natural products are important source of new therapeutics. Due to development of resistance of pathogenic microorganisms to antibiotics, tb resistance, malaria resistance etc. biological diversity of ocean offers great promise as a source of drugs for the future. Peptides transfer information and regulate life which is involved in biological signal mechanism. Bioactive peptides are very significant settled products that are present in many marine species that interested pharma industry worldwide which aspire them for use in the remedy of various diseases.

India spreading a coastline above $8000 \mathrm{~km}$ with a wide variety of marine habitats and organisms with potential to tap the resources in a better way to explore for clinical ailments. In terms of new drug discovery, Indian institutes such as: national institute of oceanology - Goa. Central drug research institute - Lucknow. Bose institute - Kolkata. Regional research laboratory - Bhubaneshwar. Central institute of fisheries education - Mumbai.

Contribute to the research activity from marine sources. Many other Indian institutes, universities, and pharmaceutical companies have also recognized the significance of this subject. ${ }^{3}$

\section{SOURCES OF MARINE DRUGS}

Ocean flora and fauna - sponges, coelenterates (sea whips, sea fans and soft corals), tunicates, echinoderms (star fish, sea cucumbers etc.) and bryozoans and a wide variety of marine microorganisms.

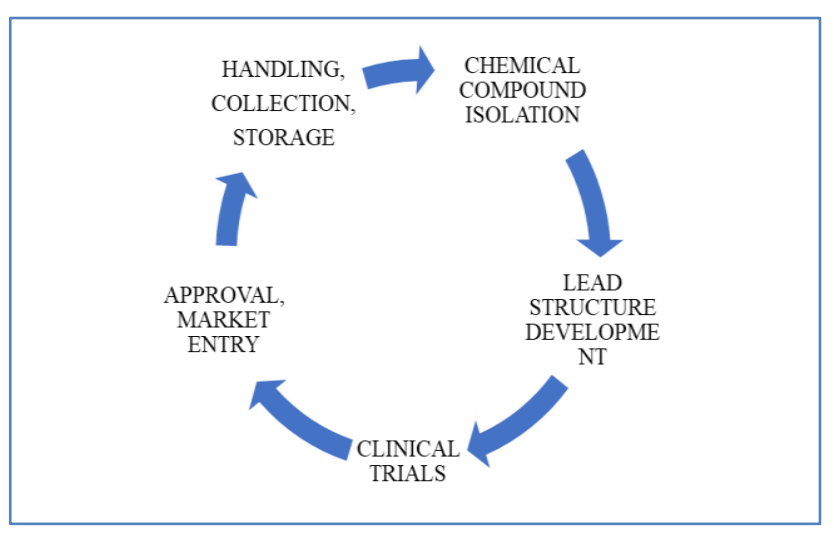

Figure 1: Marine drug development.
HANDLING, COLLECTION, STORAGE OF MARINE MICROORGANISMS

\section{Handling}

Caution should always be taken in handling marine organism. Proper protective equipment like gloves and eye protective always be worn. Hydroids and sponges have highly irritating compounds which causes immediate itching in some people e.g.: Tedania ignis (Fire sponge).

\section{Collection}

Very simple and inexpensive to very complicated expensive. Collection from near or on shoes are ready via beach combing, wading or snorkeling, from deep water via dredging-invasive technique, from depths that cannot be achieved by scuba diving, submersibles can be used. Documentation is needed. Record the longitude, latitude, depth, water temperature, salinity and dates of collection. Careful description of organism like color, odour, morphology, mucus thickness and reproductive state is noted. It is common to find worms, mollusks, copepods, brittle stars, small fish and even larger marine invertebrates.

\section{Storage}

Many begin to decompose; therefore, organisms need to be either dried, extracted or frozen immediately to reduce spoilage and chemical degradation. After collection, organisms are frozen immediately at $-20^{\circ} \mathrm{c}$. Some organisms are placed into an alcohol such as methanol, ethanol or isopropanol. Algae are air dried and stored at room temperature.

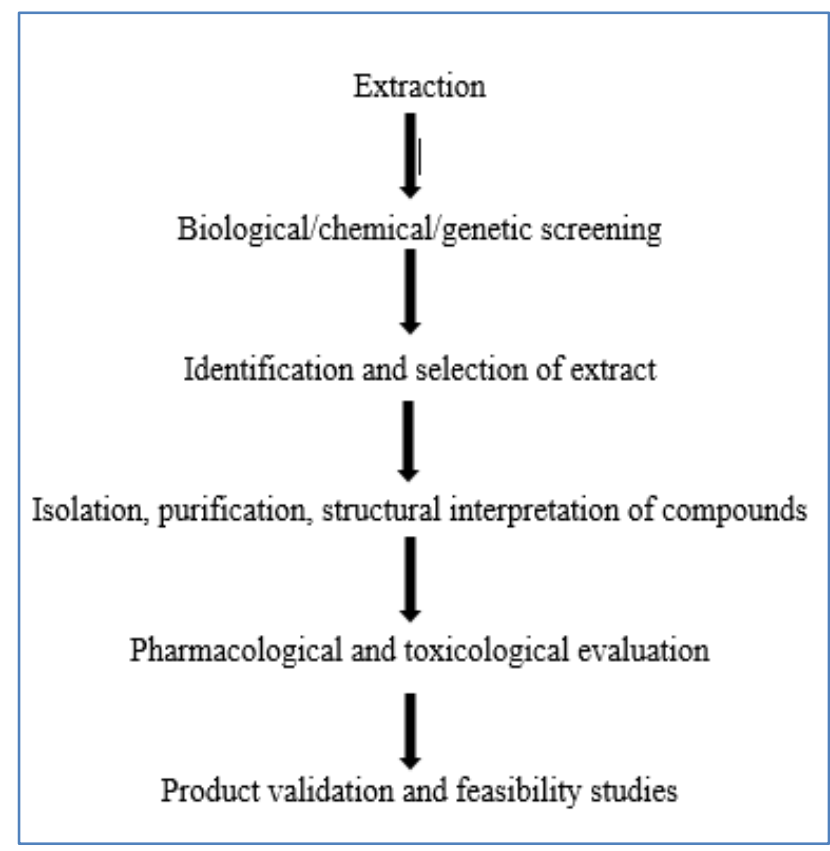

Figure 2: Chemical compound isolation. 
Table 1: Classification of marine drugs.

\begin{tabular}{|c|c|}
\hline Marine drugs & Classification \\
\hline Anti-bacterial & $\begin{array}{l}\text { Eicosapentanoic acid, a PUFA, } \\
\text { isolated from diatom of } \\
\text { Phaeodactylum tricornutum, } \\
\text { against gram +ve, gram -ve, MDR, } \\
\text { and } S \text {. aureus }\end{array}$ \\
\hline $\begin{array}{l}\text { Anti- } \\
\text { inflammatory }\end{array}$ & $\begin{array}{l}\text { Mediterranean sponge species } \\
\text { Spongia officinialis - invivo study } \\
\text { on rat model of carragenan - } \\
\text { induced paw edema. }\end{array}$ \\
\hline $\begin{array}{l}\text { Neuro } \\
\text { protective }\end{array}$ & $\begin{array}{l}\text { Green seaweed Ulva reticulata- } \\
\text { neuroprotection by inhibiting } \\
\text { acetyl and butyryl cholinesterases, } \\
\text { in treatment of alzheimer's }\end{array}$ \\
\hline Anti-parasitic & $\begin{array}{l}\text { Extracts of Sarcotragus sp.- } \\
\text { tunisian sponge experimented in } \\
\text { invitro for anti-leshmanial activity. }\end{array}$ \\
\hline Anti-viral & $\begin{array}{l}\text { Fresh marine sponge - Celtodoryx } \\
\text { girardae for anti-HSV activity. }\end{array}$ \\
\hline Anticancer & $\begin{array}{l}\text { Bryostatin from Bryozoan bugula } \\
\text { neritina against leukemia cells } \\
\text { KLH (keyhole limpet } \\
\text { hemocyanin) from Megathura } \\
\text { crenulata (gastropod sp.) for } \\
\text { Bladder ca. }\end{array}$ \\
\hline Analgesic & $\begin{array}{l}\text { Ziconotide }-1{ }^{\text {st }} \text { FDA approved } \\
\text { drug in treatment of pain, } \\
\text { extracted from marine snail Conus } \\
\text { magus. }\end{array}$ \\
\hline Anti-microbial & $\begin{array}{l}\text { Cephalosporin } \mathrm{C} \text { derived from } \\
\text { marine fungus Cephalosporium } \\
\text { acremonium. }\end{array}$ \\
\hline Anti-malarial & $\begin{array}{l}\text { Isonitrile containing Acanthella sp. } \\
\text { (Japanese sponge). }\end{array}$ \\
\hline
\end{tabular}

OCEAN AS A SOURCE OF NEW NUTRITIONAL VALUES

Proteins in fish have positive role in reducing blood cholesterol and have protective effect in diabetic renal diseases. Fish oil is an essential rich source of omega-3 fatty acids, reduces risk of heart disease and promote healthy skin. Fish lipids: approximately $50 \%$ of fatty acids in lean fish and $25 \%$ fatter fish are PUFAS. Marine microalgal species contains high quantities of DHA (docosahexaenoic acid) and arachidonic acid with major proportion of PUFA believed to result in higher levels in the brain - recommended as nutritional additives for infants. Squalene is an isoprenoid compound found in liver oil of deep-sea sharks, got immense medical applications.

Marine-derived nutritional supplements, or "nutraceuticals," present a new opportunity for research in the application of MNP to human health issues, one important application of the many bioactive compounds derived from the marine environment is their use as molecular probes, molecules broadly defined as nondrug substances which can be used to probe the foundations of important biochemical events. ${ }^{4}$

\section{Shows drugs under clinical trials}

\section{Phase III trial}

Eribulin Mesylate (E7389) or halichondrin B - polyether macrolide natural molecule extracted from marine sponges- anticancer. Soblidotin (auristatin PE). This drug is undergoing trials in clinical phases I, II, and III with different companies who are trying to use it as a weapon to specific monoclonal antibodies linked via customized peptides. ${ }^{5}$ Tetrodotoxin- a very well known "marine toxin," and highly substituted guanidine-derivative, neuropathic pain. ${ }^{6}$

Table 2: Showing approved drugs of marine pharmacology.

\begin{tabular}{|llll|}
\hline Compound name & Source & Moa & Indication \\
\hline Cytarabine (Ara-C) & $\begin{array}{l}\text { Spongothymidine from } \\
\text { Caribbean sponge sp. }\end{array}$ & $\begin{array}{l}\text { DNA synthesis inhibitor } \\
\text { (S-phase) }\end{array}$ & Leukemias \\
\hline Vidarabine (Ara-A) & $\begin{array}{l}\text { Spongouridine - } \\
\text { Streptomyces antibioticus }\end{array}$ & $\begin{array}{l}\text { Competitive inhibitor of } \\
\text { viral DNA polymerase }\end{array}$ & Herpes simplex viral infections \\
\hline Ziconotide & $\begin{array}{l}\text { Venom of marine snail } \\
\text { Conus magus }\end{array}$ & $\begin{array}{l}\text { N-type voltage gated } \\
\text { calcium channel blocker }\end{array}$ & Analgesic \\
\hline Trabectedin & $\begin{array}{l}\text { Tunicate sp.- Ecteinascidia } \\
\text { turbinate }\end{array}$ & $\begin{array}{l}\text { Genetic transcription } \\
\text { processes and DNA repair } \\
\text { machinery }\end{array}$ & $\begin{array}{l}\text { First anticancer molecule } \\
\text { approved - EU soft tissue } \\
\text { sarcoma and ovarian cancer. }\end{array}$ \\
\hline
\end{tabular}

Phase II trial

DMXBA (GTS-21) - aquatic worms of phylum Nemertea- beneficial for CNS (schizophrenic pts.), improves cognition. Plitidepsin- natural marine depsipeptide- Tunicate aplidium albicans. S/E- muscle toxicity, fatigue, diarrhea, rash. Elisidepsin (PMO2734) - it is currently undergoing development in phase II with primary evidence of antitumor potency with encouraging therapeutic index. PM00104 (zalypsis) - extracted from pacific nudibranch's varieties of sponges and tunicates. Plinabulin (NPI-2358)- It is a fully laboratory made analog of the natural product halimide originally derived from marine Aspergillus sp. CNC-139 (from Halimeda 
lacrimosa) and phenylahistin extracted from Aspergillus ustus - functions by inhibiting the polymerisation of tubulin. ILX-651 (synthadotin) - different types of cancer.

\section{Phase I trial}

Leconotide (AM-336)- similar to ziconotide - treatment of cancer. Enfortumabvedotin- Immunotherapy. Vorsetuzumab mafdotin (SGN-75)- relapsed and refractory non-hodgkin's lymphoma. Bryostatin 1bryozoan B. neritina- alzheimer's disease. Hemiasterlin (E7974)- marine sponges. Marizomib (NPI-0052, Salinosporamide A)- marine actionomycete Salinispora tropica - treatment of cancers.

\section{$\begin{array}{llll}\text { CURRENT STATUS IN MARINE } & \text { M }\end{array}$ PHARMACOLOGY}

Modern technologies have opened vast areas of research for extraction of biomedical compounds from oceans and seas. Sessile marine kingdom involves sponges, bryozoans, tunicates lacking morphological defensive structures have developed marine derived secondary metabolites which are the most interesting drug candidates to investigate. Extensive work has been conducted in targeting uncultivable microbes of marine sediments and sponges. Few drugs are in clinical trials and many more are in pipeline.

\section{Sponges}

Holds anticancer, anti-inflammatory, antibiotic properties. Studies are focused on biological activity of toxic compounds that repel predators. Sponges are known to be rich source of terpenoids which has shown strong antibiotic activity. Terpenoids is an active ingredient in drugs like variabilins and hydroquinone with both analgesic and anti-inflammatory properties. ${ }^{7}$ Manzamine alkaloid derived from Indonesian sponge targets malaria, tb, leishmania. It can be planted and cultured in sea or aquarium by cutting from parent. Discodermolide - deep water sponges of the genus Discodermia is effective against breast and other types of cancer. Lithoplocania lithistoides a polyketide plocabulin, entered clinical development. In advanced preclinical trials, halichondrin B, derived from a New Zealand deep water sponge, Lissodendoryx sp.

\section{Algae}

Several scientists reported that sulphated polysaccharides and oligosaccharides isolated from marine algae have antiviral, immuno-inflamatory, antithrombotic, antilipidemic, and antioxidant activities. $^{8}$ It Possess antioxidants, anticancer, and antiviral properties.

Algae species $\mathrm{S}$. platensis is hepatoprotective on carbontetrachloride induced liver injury investigated in rats. Brown macro algae lessonia - polyphenol rich extracts modulate gut microbiota in high fat diet and streptozocin induced diabetes mellitus in rats. The ability to produce the bioactive compound specially by green algae is boon to the pharmaceutical research.

\section{Tunicates}

Includes seas quirts, chemical metabolites with properties of antifungal, antibacterial, cytotoxic, antimalarial, inhibition of protein kinase $\mathrm{C}$ is noticed. Didemnin B derived from tunicates has strong antiviral property against DNA and RNA viruses.

Recently didemnins are also derived from marine alpha proteiobacteria Tistrella mobilis, T. bauzanesis, culturing tunicates on a large scale may be possible and the economics of doing are attractive.as tunicates have few predators, their removal from sea may not have profound ecological impacts. Main area of interest in screening from tunicates is anticancer drugs followed by antimalarials.

\section{Sea whip}

Pseudopterosins have anti-inflammatory and analgesic properties. Inhibits synthesis of eicosanoids in polymorphonuclear lymphocytes. The activity of extreme selectivity towards the target of these organisms attracted researchers.

\section{Sea weeds}

Holds the wealth of mineral elements from sea.

\section{Squalamine}

Derived from the liver of dog fish shark, used in carcinoma and diabetic retinopathy. Geranyl phenazine diol anticholinesterase inhibitor produced by streptomyces isolator.

Fucoidan derived from focus vesiculosus can be novel pharmaceutical compound in treatment of ovarian cancer.

Marine fungus arthrinium in prostate cancer lines - PC 3 assay. Sea cucumber - tegument extract - antiviral activity and human rota virus.

Octopus vulgaris derived from taurine rich water-soluble extract is hepatoprotective by regulation of BCL 2 signalling.

Alzheimer's disease is a neurodegenerative disorder with incurable symptoms. Current drugs show temporary effect for restricted time period. Some marine derived organic compound (example cytarabine, trabectedin, eribulin and ziconotide) found effective in neurodegeneration. ${ }^{9}$ 


\section{ASSESTS AND DEMERITS OF MARINE PHARMACOLOGY}

The ocean portrays rich source incessantly novel compounds with great potential as pharmaceuticals, nutritional supplements, cosmetics, enzymes where each of these bioproducts has a strong future market value.

Lifesaving drugs are mainly found plenty in microorganisms, algae, invertebrates. In recent years, markable digit of novel metabolites with potential pharmacological properties have been discovered from marine organisms.

Approximately 25,000 compounds have been screened, about 30 of them are in clinical trials and 10 of them are commercially marketed (Sharma et al, 2005). Oceans continuously provide new opportunities for the discovery of marine-derived antibiotics. Increased refinement in the tools to explore the seas has expanded the habitats and greatly improved the chances for discovery of new species and chemical compounds they produce.

The reasons for strong showing of drug discovery from marine natural products can be attributed to detail carbon skeletons and human bodies accept these molecules with minimal manipulation. Furthermore, advancement in metabolic engineering of microorganisms synergise marine product exploration more easily than mammalian and plant cells.

According to American cancer society, global burden of cancers is expected to grow as high as 27 million new cases and 17.5 million cancer deaths by 2050 . Current research effort in cancer therapy are aimed to disturb transcription process involved in maintenance of oncogenic state. Clinical investigation in the marine natural products has promising results e.g.; Lurbinectedin (trabectedin analogue) - from Caribbean sack like sea squirt, Ecteinascidia turbinate.

According to an estimate by Sawadogo et al, in 2011 available promising anticancer compounds of marine origin can be divided into different classes of chemicals majority represented by terpenes and terpenoids $(40.5 \%)$ following by peptides (19\%), macrolides $14.3 \%$ ), and alkaloids (12\%). Among them, $50 \%$ are first time looked upon as anticancer agents.

Certain inhibitors of the signal transduction pathways involved in cancer development have been obtained from marine organisms, and further studies are under process to attain evidence on their efficacy in cancer therapy. ${ }^{10}$

Certain fishes have rapidly gaining acceptance as a promising animal model for pharmacological and toxicological screening.
The bicolor damselfish, Pomacentrus partitus, is the first animal model for one type of human cancer that involves nervous system, neurofibromatosis type - I.

\section{Zebra fish}

A model for marine peptide-based drug screening. Concurrent technological advances have significantly improved the genetic tractability and unique advantage of in vivo imaging in zebrafish, providing a means to dissect the molecular pathways underlying tumor initiation, progression and metastasis. ${ }^{11}$ It is an important model for understanding the mechanisms of development and diseases such as cancer. Cheaper than mice for experimentation. Grows at faster rate. It produces hundreds of off springs with handful of embryos for scientists to study. Transparency of zebra fish facilitated scientists easily to examine internal structures. Shares 70 $\%$ genes with the humans. It has unique ability to repair heart muscle on which scientists are working on these specific factors involved in the process if it helps to develop ways of repairing human heart. Retinal angiogenesis can be induced in zebra fish by transgenic fish which helps in study of diabetic retinopathy.

\section{MARINE COMPOUNDS AS DIAGNOSTICS AND EXPERIMENTAL TOOLS}

Marine compounds (isolated) are used not only in disease remodelling but also as diagnostics and experimental tools. Pfu, enzyme from marine thermophile pyro coccus furiosus used in PCR. GFP, green fluorescent protein isolated from jellyfish Aequorea Victoria. It is used as a biological marker for labelling of cell structures invitro and in vivo. Shimomura (Japan), Chalfie and Tsien (USA) got the Nobel prize for its detection and establishment of its applications in 2008. ${ }^{12}$ LAL- limulus amoebocyte lysate from crab Limulus polyphemus for detection of pyrogenic lipopolysaccharides from $G$-ve bacteria. Keyhole limpet hemocyanin (KLH) is a large, multisubunit, oxygen-carrying metalloprotein which is found in the hemolymph of the giant keyhole limpet Megathura crenulata, a marine mollusk, living off the coasts of California, USA. ${ }^{12}$

Although drugs derived from land are incredibly vital to human mankind, they are not sufficient to meet the needs. Ocean with huge space covers all over the world i.e., acquiring resources is feasible and these has high potential for future development in drug discovery. The rich diversity of marine biodata with its unique physiological adaptations to the harsh marine environment is providing a fruitful source for the discovery of lifesaving drugs.

\section{Demerits}

Despite the potential of numerous compounds to combat bacteria, viruses and diseases, marine sources are not extensively investigated because of many reasons. 
Identification of feasible clinical formulation also needed by experts. The lack of taxonomic knowledge for marine $\mathrm{sp}$. is a major demerit faced by marine natural products programs. Few species causing marine envenomation e.g., cnidaria, mollusca, chordata.

Additional expenses, time and specialized services of divers, submersibles are required to explore the marine organisms found in remote areas. The pharma industry loses its value and advantages by disclosure of compound from which organism it is isolated and its structure. The techniques used with marine natural products include complex screening procedures that are time inefficient, expensive and labour some. Identification of lead compounds sometimes pose a problem because it is present in low quantity, difficult to isolate. Lurbinectedin (a potential anticancer agent) for extracting $1 \mathrm{gm}$ of drug from source about 1 ton of sea squirts is needed that implies need for massive collection of sources from marine ecosystem. These compounds receive less attention though numerous bioactive compounds are of novel chemical structure and mechanism, never have been synthesized in any rational programme for designing new drugs.

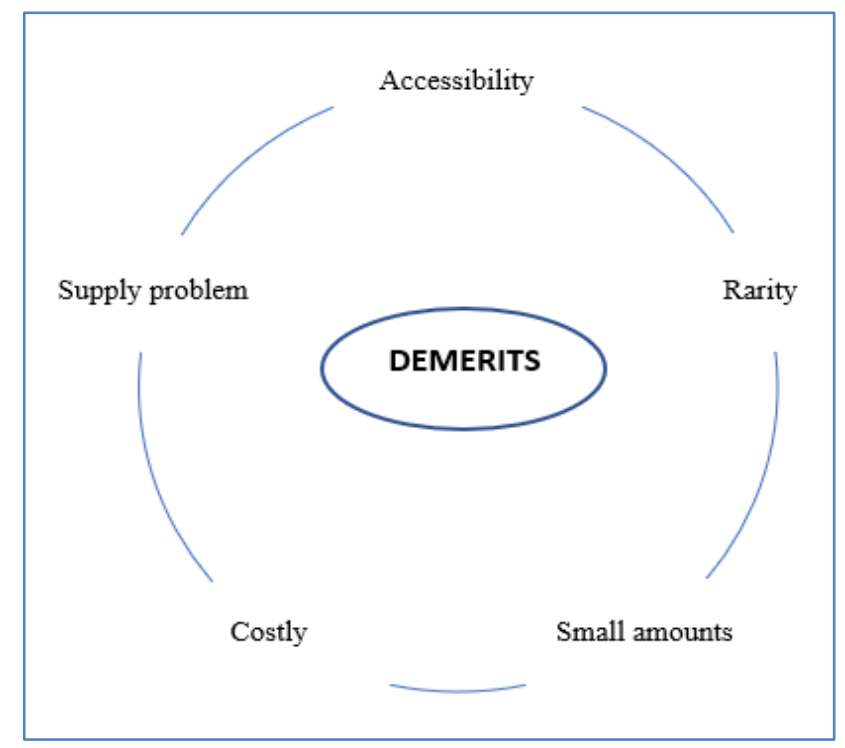

Figure 3: Demerits of marine pharmacology.

\section{CHALLENGES ASSOCIATED WITH MARINE PHARMACOLOGY}

Though $70 \%$ of earth's surface is covered with oceans with rich source of marine products, still major proportion of these areas are inaccessible to researchers. And it needs a still good teamwork of researchers and oceanographer. Application of advanced technology in manufacturing machinery to collect the samples from the depths of the sea helps in reducing manpower.

Different environmental conditions result in the production of different metabolite every time from the same organism. Marine natural products show symbiotic association, are difficult to develop separately because their growth depends directly or indirectly on host. The major drawback for the invitro studies of the products is most of important genes remains silent.

The conservation and protection of these resources and ecosystem is major challenge of which global warming is massive trending threat. Critical point is that while developing drugs from marine sources, marine environment has to be preserved without harming. To overcome the issue of regular supply, the use of natural resources should be under control and need to favour the growth of marine organisms in its natural environment by farming which is also known as "Mariculture." 13 Another option is to culture the marine organisms under artificial conditions by the process called as "aquaculture". The indepth study of chemical structure focus on discovery of lead compound, where genetic engineering plays a key role in targeted approach. Synthesized or hemi synthesized must be done with reference to compound derived from biological source. Incorrect classification of species may compromise entire drug discovery project. The main emphasis is given in search of drugs for dreadful human diseases such as cancer and AIDS. Another challenge is the adequacy of marine resources of particular compound. Pharma industry will try to invest in to trials, if that particular lead compound is effective. Only if supply can be addressed in economically and ecologically feasible fashion, marine drugs will get a chance in the market. Government also should take appropriate measures in the development of marine drug in terms of finances, safety etc.

\section{CONCLUSION}

Modern medicine has come a long way from the discovery of penicillin saving thousands of lives wounded in world war 2 and now standing at the zenith of technological development aiding in the discovery of new drugs. But the terrestrial resources we have been using is diminishing, thanks to the continual discovery of new diseases and ailments without effective therapy. An answer to this impasse lies in the usage of marine flora and fauna for the manufacture of new pharmaceuticals. This branch of pharmacognosy pioneered by Bergmann evolved from the two drugs (Ara $\mathrm{C}$ used in the treatment of ALL and Ara A used in herpes infection) and has been on the $5^{\text {th }}$ pedestal discovering the unexplored realms of marine biology.

It's estimated that $70 \%$ of the world's land is covered in water and there lies Representatives of all the phyla of species of which 12 are exclusively marine. With the cultivation of marine microbes which are once considered in culturable has been able to lift our hopes of sustainable resources for new drug discovery owing to the efforts of Davidson, Fenical, Kobayashi and Okami. Such a diverse resource lying unutilised is a humongous mistake considering the need for new drugs which can effectively 
treat cancer, AIDS, auto immune disorders and the everincreasing antibiotic resistant disorders. The answer to all these plights lies in the marine environment waiting for us to harness the key to a successful identification and production and thereby providing for the needful community of humans.

So, the task Infront of us, is to improve our technology or modify it in a way to harvest marine ecosystem and thereby new medicines in a cost-effective way. Let's not forget that the conclave requiring effective medicine belong to the lower socioeconomic status. Most of the times especially in a developing country like India and so to reach them, the medicine should be of low cost.

The arena of marine sciences is not only a platform for the discovery of new pharmaceuticals but also an aid to identify drug pharmacodynamics at cellular level.

\section{ACKNOWLEDGEMENTS}

The authors are thankful to Dr. T. Chakradhar (HOD, department of pharmacology), Osmania medical college, Hyderabad for the constant support and motivation.

Funding: No funding sources

Conflict of interest: None declared

Ethical approval: Not required

\section{REFERENCES}

1. Malve H. Exploring the ocean for new drug developments: Marine pharmacology. J Pharm Bioallied Sci. 2016;8(2):83-91.

2. Donia M, Hamann MT. Marine natural products and their potential applications as anti-infective agents. Lancet Infect Dis. 2003;3:338-48.
3. Thakur NL, Thakur AN, Muller WEG. Marine natural products in drug discovery. Natural Product Radiance. 2005;4:471-7.

4. Marine pharmacology: Potential, challenges, and future in India.

5. Kanase HR, Naman KM, Singh, Mayer AM, Glaser $\mathrm{KB}$, Cuevas $\mathrm{C}$, et al. The odyssey of marine pharmaceuticals: A current pipeline perspective. Trends Pharmacol Sci. 2010;31:255-65.

6. Moczydlowski EG. The molecular mystique of tetrodotoxin. Toxicon. 2013;63:165-83.

7. Alice OD, Elegbede IO. Impact and Challenges of Marine Medicine to Man and its Environment. Poult Fish Wildl Sci. 2016;4:160.

8. Jiao G. Chemical Structures and Bioactivities of Sulfated Polysaccharides from Marine Algae. Mar Drugs. 2011;9:196-223.

9. Patrizia P. New Drugs from Marine Organisms in Alzheimer's disease. Mar Drugs. 2016;1:5.

10. Bhatnagar I, Kim SK. Marine antitumor drugs: Status, shortfalls and strategies. Mar Drugs. 2010;8:2702-20.

11. Etchin J, John P, Kanki A. Zebrafish as a Model for the Study of Human Cancer. Thomas Look Volume. 2011;105:309-37.

12. Lindequist U. Marine - Derived Pharmaceuticals Challenges and Opportunities. Biomol Ther (Seoul). 2016;24(6):561-71.

13. Structural revisions of natural products by total synthesis Maier MEN at Prod Rep. 2009;26(9):110524.

Cite this article as: Sruthi V, Grace NS, Monica N, Kumar VM. Marine pharmacology: an ocean to explore novel drugs. Int J Basic Clin Pharmacol 2020;9:822-8. 